\title{
Exigências Líquidas de Energia e Proteína de Tourinhos de Dois Grupos Genéticos Alimentados com Dietas de Alto Teor de Concentrado
}

\author{
Maria Luisa de Medeiros Bulle ${ }^{1}$, Fábio Garcia Ribeiro ${ }^{2}$, Paulo Roberto Leme ${ }^{3}$, Evaldo Antonio \\ Lencione Titto $^{3}$, Dante Pazzanese Duarte Lanna ${ }^{4}$
}

RESUMO - Avaliou-se a composição corporal de 42 tourinhos 1/4 B. indicus $x$ 3/4 B. taurus, de raça paterna Britânica (Shorthorn) ou Continental (Guelbvieh) com 9 meses e $243 \mathrm{~kg}$ de peso vazio inicial (PVzi). Destes, seis animais foram abatidos para obtenção da composição corporal inicial do lote. Os 36 animais restantes foram confinados com dietas contendo 9 , 15 e $21 \%$ de bagaço de cana in natura (BIN) na MS. Não houve efeitos significativos da interação entre tipos raciais e níveis de fibra para as variáveis analisadas. O efeito do tipo racial não alterou a composição do ganho de peso vazio (GPVz), tendo os animais Britânicos apresentado 28,9\% de gordura e 3,75 Mcal/kg, enquanto os animais Continentais apresentaram $28 \%$ de gordura e 3,67 Mcal/kg de GPVz. Os animais Britânicos apresentaram teores numéricos maiores de gordura e energia, apesar de apresentarem média de PVzi e ganho de peso vazio final (GPVzf) menores que os Continentais. O efeito de fibra não foi significativo, mas animais recebendo dietas com $15 \%$ de BIN apresentaram GPV numericamente maior (1,2 kg/d), que os animais que receberam $9 \%$ e $21 \%$ de $\operatorname{BIN}(1,1 \mathrm{~kg} / \mathrm{d})$. Os diferentes níveis de BIN não alteraram a composição do ganho, mas a composição do GPVz dos animais que receberam 15\% de BIN apresentaram maiores teores numéricos de lipídeo e energia, $31 \%$ e 3,94 Mcal/kg de GPVz. Os animais submetidos aos tratamentos 9 e $21 \%$ de BIN apresentaram respectivamente, 28,6\% e $25,7 \%$ de lipídeo e 3,72 e 3,46 Mcal/kg de GPVz. A composição do GPVz e as exigências líquidas de energia e proteína dos tourinhos $3 / 4$ europeus filhos de vacas Caracu x Nelore com touros Guelbvieh ou Shorthorn foram semelhantes às observadas para machos não castrados de tamanho corporal grande ou grau de estrutura corporal próximo a 8 na escala 1-9.

Palavras-chave: bagaço de cana, bovinos de corte, composição corporal, concentrado, exigências nutricionais, níveis de fibras

\section{Net Energy and Protein Requirements of Young Bulls of Two Genetic Groups Fed High Concentrate Diets}

\begin{abstract}
Body composition of 42 crossbreed bulls $1 / 4$ B. indicus x $3 / 4$ B. taurus of either Continental (Guelbvieh) or British (Shorthorn) paternal breed and Caracu x Nelore cows ( 9 months old and initial empty body weight of $243 \mathrm{~kg}$ ), were evaluated. Six animals were slaughtered after the adaptation period to obtain the initial body composition. The other 36 animals were fed diets formulated with 9, 15 and $21 \%$ of sugar cane bagasse in natura (BIN) and concentrated. There were no significant interaction of genetic breed and level of BIN for any variable. There was no effect on paternal breed on the composition of empty body gain (EBG), with British animals with 28.9\% lipid and $3.75 \mathrm{Mcal} / \mathrm{kg}$ and Continental animals 28.0\% lipid and 3.67 Mcal/ $\mathrm{kg}$ in the EBG. British animals had numerically greater fat content in the gains despite the lower initial and final empty body weights. Animals receiving diets with $15 \%$ BIN had higher rates of empty body gain, $1.21 \mathrm{~kg} / \mathrm{d}$, while animals receiving 9 and $21 \%$, gained $1.1 \mathrm{~kg} / \mathrm{d}$. Roughage level or breed did not alter final empty body composition, however, composition of the empty body gain of animals fed $15 \%$ BIN had higher lipid and energy content (31\% and 3.94 Mcal/kg EBG) compared to the animals recieving 9 and $21 \%$ BIN diets (28.6 and $25.7 \%$ lipid; 3.72 and $3.46 \mathrm{Mcal} / \mathrm{kg}$ of EBG, respectively). These results can be explained by the fact that the animals were young intact males with low final body weights. Composition, of the EBG (net energy and protein requirements) of $3 / 4$ B. taurus $\mathrm{F}_{2}$ crossbreed bulls from Caracu $\mathrm{x}$ Nelore cows were consistent with NRC equation for large frame bulls or frame score 8 in a 1-9 scale.
\end{abstract}

Key Words: beef cattle, body composition, concentrate, fiber, requirements, sugarcane bagasse

\footnotetext{
${ }^{1}$ Pós-graduanda, Laboratório de Crescimento e Nutrição Animal, ESALQ/USP, bolsista CNPq, Piracicaba, SP. E.mail: mlbulle@hotmail.com ${ }^{2}$ Pós-graduando, FZEA/USP, Pirassununga, SP.

${ }^{3}$ Professor, Depto. Zootecnia, FZEA/USP, Pirassununga, SP.

${ }^{4}$ Professor, Depto. Produção Animal, ESALQ/USP, bolsista do CNPq, Piracicaba, SP. E.mail: dplanna@esalq.usp.br
} 


\section{Introdução}

A determinação da composição corporal dos animais é fundamental para a avaliação do valor nutricional dos alimentos e em estudos do crescimento animal. O crescimento normal de um animal deve ser entendido como um conjunto de modificações físicas, químicas e funcionais de seu organismo (Boin et al., 1994), onde há deposição dos componentes químicos. É possível estudar a eficiência energética e as exigências nutricionais do animal pelo conhecimento da composição química do ganho de peso.

Para se determinar a composição corporal de animais, o método mais preciso envolve o abate do animal e a moagem de todos os tecidos corporais para posteriores análises laboratoriais. Entretanto, essa prática, como rotina experimental, é extremamente dispendiosa e trabalhosa.

Estudando diversas metodologias de estimativa da composição, Lanna (1988) verificou que o uso da composição de cortes das costelas de bovinos produziu resultados mais confiáveis para se estimar a composição química corporal do que a gravidade específica ou as técnicas in vivo. Hopper (1944) encontrou coeficientes de determinação para regressão do extrato etéreo no corte da $9^{\mathrm{a}}-10^{\mathrm{a}}-11^{\mathrm{a}}$ costelas no corpo vazio de 0,96 e sugeriu que a melhor forma de se estimar a porcentagem de água e gordura seria através da composição química do corte das costelas. Henrique et al. (1999b) estabeleceram equações correlacionando a composição química da $9^{\mathrm{a}}-10^{\mathrm{a}}-11^{\mathrm{a}}$ costelas com a composição química corporal especificamente para bovinos $5 / 8 \mathrm{~B}$. taurus, visto que as equações desenvolvidas para Nelore por Lanna (1988) não foram adequadas para este genótipo.

O nível de energia na dieta consumida pelo animal pode alterar a proporção de tecidos magros ou tecidos gordurosos depositados. Dietas de alto concentrado, onde o nível de energia consumida é alto, levam a um aumento na taxa de ganho e na concentração de gordura dos tecidos depositados (Fox et al., 1992). Essa partição de energia para deposição de lipídeos e proteína, em animais com diferentes potenciais de deposição, foi estudada por Robelin \& Geay (1983), em animais recebendo dois níveis de energia. Uma maior proporção de energia foi retida como proteína nos animais com alto potencial de retenção de proteína, enquanto que um aumento da energia retida como lipídeos ocorreu nos animais com menor potencial de crescimento principalmente nas dietas de maior teor de energia. Assim, o tipo de animal parece influir na composição do ganho de peso em função da variação do nível de alimentação.

Os requerimentos de energia líquida para crescimento (ELg) são estimados como a soma de energia depositada na forma de proteína e gordura. O NRC $(1984,1996)$ estima as exigências de energia para ganho, com base no peso médio e ganho de peso diário. Os requerimentos são ajustados de acordo com as condições específicas, como tamanho do animal, sexo e uso de implantes e hormônios. O sistema de Cornell (Fox et al., 1992), usa equações semelhantes às do NRC (1984) para predizer os requerimentos nutricionais, consumo e eficiência de utilização da energia dos alimentos. Entretanto, são considerados os efeitos de vários fatores sobre estas equações como tamanho e condição corporal, estádio de crescimento, frações das proteínas e dos carboidratos nos alimentos, suas taxas de digestão e passagem e condições ambientais.

Existem poucos dados das exigências líquidas de mestiços zebuínos quando comparados ao grande volume de informações disponíveis para a estimativa das exigências nutricionais de taurinos (NRC, 1996). Diversos grupos vem pesquisando o efeito das dietas (natureza do alimento, concentração energética, tipo de fibra, período de alimentação etc) e dos animais (raça, idade, sexo, condição corporal ou nível de nutrição anterior) sobre o crescimento e a composição do ganho de peso de bovinos em crescimento. No Brasil, a partir da década de 80, trabalhos foram conduzidos no sentido de obter informações que permitam fazer estimativas de exigências nutricionais que mais se adequem às condições brasileiras (Lana et al., 1992; Leme et al., 1994; Boin, 1995; Fontes, 1995; Lanna et al., 1995; Leme et al. 1997; Alleoni et al., 1997; Henrique et al., 1999a,b) e adaptar informações básicas oriundas de outros países à realidade brasileira (Lanna et al., 1999).

A redução da proporção de volumoso está geralmente ligada a aumento no teor de energia da dieta e, conseqüentemente, na taxa de ganho e proporção de gordura no ganho. Outro aspecto importante é que a manipulação do teor de volumoso deve ser feita de forma a atender as exigências mínimas de fibra efetiva para ruminantes. Programas de formulação capazes de encontrar o teor de energia ótimo para maximizar lucro devem incluir restrições para manter os níveis de fibra efetiva que evitem o aparecimento de distúrbios metabólicos. Estes valores tem se mos- 
trado diferentes para zebuínos e animais europeus e seus cruzamentos (Lanna et al., 1999).

Uma possível fonte de volumoso para dietas de confinamento no Brasil seria o bagaço de cana-deaçúcar in natura (BIN). Este alimento apresenta um grande excedente e tradicionalmente vem sendo utilizado após tratamento físico ou químico. Poucos estudos foram conduzidos com o BIN em dietas de alto concentrado (Henrique et al., 1999a) e não se conhece o nível ideal de utilização neste tipo de dieta. Esta questão é importante, pois o bagaço sem tratamento não se caracteriza como boa fonte de fibra íntegra, em função de conter grande proporção de partículas de pequeno tamanho e possibilidade de crescimento de fungos.

O objetivo deste trabalho foi obter dados de composição corporal e as exigências líquidas de energia e proteína de mestiços $\mathrm{F}_{2}$ de tipos genéticos paternos Continentais e Britânicos filhos de vacas Caracu x Nelore (bezerros 3/4 sangue Europeu, 1/4 sangue Zebuíno e $1 / 2$ sangue de animais adaptados) que possam parametrizar modelos como o CNCPS (Fox et al., 1992) e o RLM (Lanna et al., 1999). Os resultados obtidos podem ser utilizados para atualizar as equações destes modelos, permitindo a análise dos requerimentos nutricionais de forma dinâmica e cada vez mais acurada e precisa. Os animais foram alimentados com dietas de alto concentrado com três níveis de bagaço de cana-de-açúcar in natura com objetivo de avaliar o BIN como único volumoso.

\section{Material e Métodos}

Foram confinados 42 tourinhos cruzados $(3 / 4$ de sangue Europeu, 1/4 sangue Zebu), com idade média de 9 meses e peso vazio inicial (Pvzi) de $243 \mathrm{~kg}$ ao início do período experimental em 18 baias parcialmente cobertas, dois animais por baia. O período de confinamento foi de julho de 1998 a janeiro de 1999. Os animais eram filhos de vacas Caracu x Nelore, sendo as raças paternas a Britânica Shorthorn ou a Continental Guelbvieh.

Os animais foram distribuídos aleatoriamente dentro da instalação e receberam durante 42 dias de adaptação uma dieta com níveis crescentes de volumoso até chegarem a $21 \%$ de BIN. Após esse período, foram abatidos seis animais para determinação do peso vazio e da composição química corporal inicial do lote. Os animais restantes foram alimentados por mais 139 dias. O volumoso utilizado durante o experimento foi bagaço de cana-de-açúcar in natura (BIN) e o concentrado composto de farelo de soja, soja extrusada, milho, e polpa de citrus. As dietas continham três níveis de BIN- 9, 15 e $21 \%$ da matéria seca total (Tabela 1) e foram balanceadas de acordo com o modelo do Cornell Net Carbohydrate and Protein System - CNCPS (Fox et al., 1992), para atender as exigências de proteína degradável no rúmen e proteína metabolizável para o animal, bem como as exigências de aminoácidos e peptídeos no rúmen.

Os alimentos foram fornecidos na forma de ração completa, em duas refeições diárias e amostras de alimentos e sobras coletadas para análise. O teor de matéria seca foi avaliado no BIN semanalmente e as dietas ajustadas em função dos resultados. As pesagens dos animais foram realizadas no início do período de adaptação, no início do período experimental e a cada 28 dias até o abate, sempre com jejum hídrico e alimentar de 16 horas.

Ao final do período experimental, os animais foram abatidos para determinação da composição

Tabela 1 - Composição das dietas experimentais (\% na matéria seca)

Table 1 - Composition of the experimental diets (\% in the dry matter) Ingrediente Nível de bagaço in natura

Ingredient $\quad$ Level of in natura sugarcane bagasse

\begin{tabular}{|c|c|c|c|}
\hline & $9 \% \mathrm{BIN}$ & $15 \% \mathrm{BIN}$ & $21 \% \mathrm{BIN}$ \\
\hline Bagaço de cana & 9,0 & 15,0 & 21,0 \\
\hline \multicolumn{4}{|l|}{ Sugarcane bagasse } \\
\hline Farelo de soja & 8,5 & 9,6 & 10,3 \\
\hline \multicolumn{4}{|l|}{ Soybean meal } \\
\hline Soja extrusada & 4,5 & 4,5 & 4,5 \\
\hline $\begin{array}{l}\text { Extruded soybean meal } \\
\text { Milho moído }\end{array}$ & 45,1 & 40,9 & 37,1 \\
\hline \multicolumn{4}{|l|}{ Ground corn } \\
\hline Polpa cítrica & 31,0 & 27,9 & 25,1 \\
\hline \multicolumn{4}{|l|}{ Citrus pulp } \\
\hline Cloreto de potássio & 0,1 & 0,1 & 0,1 \\
\hline \multicolumn{4}{|l|}{ Potassium chloride } \\
\hline Sal mineralizado & 0,8 & 0,8 & 0,8 \\
\hline \multicolumn{4}{|l|}{ Mineral salt } \\
\hline Rumensin & 0,03 & 0,03 & 0,03 \\
\hline \multicolumn{4}{|l|}{ Rumensin } \\
\hline Uréia & 1,0 & 1,0 & 1,0 \\
\hline \multicolumn{4}{|l|}{ Urea } \\
\hline \multicolumn{4}{|l|}{ Nutriente } \\
\hline \multicolumn{4}{|l|}{ Nutrient } \\
\hline Proteína bruta, $\%$ & 14,6 & 14,6 & 14,5 \\
\hline \multicolumn{4}{|l|}{ Crude protein,\% } \\
\hline NDT, $\% 1$ & 78,8 & 75,4 & 72,0 \\
\hline \multicolumn{4}{|l|}{$T D N \%$} \\
\hline FDN \% & 22,43 & 26,8 & 31,23 \\
\hline$N D F \%$ & & & \\
\hline
\end{tabular}

1 Teor de nutrientes digestíveis totais estimado por Weiss et al. (1992). Total digestible nutrients content estimated by Weiss et al. (1992). 
química corporal e das características da carcaça. A estimativa da composição foi feita com base nas porcentagens de proteína, lipídeos, água e minerais obtidas através da análise química do corte da $9^{\mathrm{a}}-10^{\mathrm{a}}-$ $11^{\mathrm{a}}$ costelas, retiradas como descrito por Hankins \& Howe (1946).

Após a retirada do corte, foi feita a pesagem seguindo-se a separação física de músculos, ossos, cartilagens e gordura, pesando-os separadamente. As pesagens foram anotadas para posterior cálculo da composição física. As amostras do corte foram moídas oito vezes em moedor de grande porte (Hermann P-33 $\left.{ }^{\mathrm{A}}-3-789,15 \mathrm{HP}\right)$, homogeneizadas e amostradas em quadruplicata. Posteriormente, foram liofilizadas para determinação da concentração de água. A amostra liofilizada foi moída em liquidificador com gelo seco e analisadas para extrato etéreo (aparelho soxhlet por 20 horas), proteína (Ntotal) e cinzas (mufla a $600^{\circ} \mathrm{C}$ ).

Utilizando-se equações desenvolvidas para estimar a composição química corporal de bovinos Santa Gertrudis (Henrique et al., 1999b), com base nas porcentagens de água na seção da $9^{\mathrm{a}}-10^{\mathrm{a}}-11^{\mathrm{a}}$ costelas, determinou-se as porcentagens destes no corpo vazio.

Para estimar a porcentagem de água no peso do corpo vazio foi utilizada a média do resultado das duas equações abaixo, a partir da porcentagem de extrato etéreo e de água na $9^{\mathrm{a}}-10^{\mathrm{a}}-11^{\mathrm{a}}$ costelas.

- \% água $\mathrm{PVz}=-0,8115 \%$ extrato etéreo $+73,767$

$\left(\mathrm{R}^{2}=0,9304 ; \mathrm{Sy} \cdot \mathrm{x}=1,10\right)$

- \% água $\mathrm{PVz}=1,0559 \%$ água - 1, 9804 $\left(\mathrm{R}^{2}=0,9249 ;\right.$ Sy.x $\left.=1,14\right)$

Para estimar a porcentagem de extrato etéreo no corpo vazio foi utilizada a média do resultado das duas equações abaixo, a partir da porcentagem de água e extrato etéreo na $9^{\mathrm{a}}-10^{\mathrm{a}}-11^{\mathrm{a}}$ costelas.

- \% extrato etéreo $\mathrm{PVz}=-1,1411 \%$ água $+83,023$

$\left(\mathrm{R}^{2}=0,9091 ;\right.$ Sy.x $\left.=1,37\right)$

- \% extrato etéreo $\mathrm{PVz}=0,8708 \%$ extrato etéreo

$+1,2706\left(R^{2}=0,9017 ;\right.$ Sy. $\left.x=1,42\right)$

$\mathrm{O}$ peso do corpo vazio $(\mathrm{PVz})$ foi estimado a partir do peso da carcaça quente (PCQ), conforme a seguinte equação (Henrique et al., 1999b):

- $\mathrm{PVz}(\mathrm{kg})=1,6039 \mathrm{PCQ}+4,5108$

$\left(\mathrm{R}^{2}=0,995 ;\right.$ Sy.x $\left.=6,72\right)$.

A determinação do conteúdo corporal de energia foi feita a partir dos teores corporais de proteína e gordura e dos respectivos equivalentes calóricos (Boin, 1995).

$\mathrm{O}$ delineamento experimental foi inteiramente casualizado com arranjo fatorial $3 \times 2$, sendo dois tipos raciais (Continentais e Britânicos) e três níveis de BIN $(9,15$ e $21 \%$ na MS), com três repetições de cada tratamento. A análise de variância (teste $F$ ) foi usada para testar efeitos do tipo racial, nível de fibra e da interação entre ambos. Para comparação de médias foi usado o teste Tukey. Todas as análises estatísticas foram realizadas usando o programa SAS (1997).

\section{Resultados e Discussão}

Os resultados de composição química corporal ao abate e das taxas de deposição de tecidos ao longo do período de confinamento estão apresentados nas Tabelas 2 e 3 . A composição química corporal do ganho de peso ocorrido entre o final do período de adaptação e abate estão apresentados na Tabela 4 . Como esperado, para todos as variáveis estudadas não houve efeitos significativos da interação entre tipos genéticos paternos (Britânicos e Continentais) e os níveis de volumosos $(9,15$ e $21 \%$ de BIN na MS da dieta). Isto se explica pelo fato de que todas as dietas são caracterizadas por altos níveis de concentrado e em função dos animais terem composição genética bastante similar.

Embora tenha sido observada tendência para maior deposição de gordura para os animais de raça paterna Britânica, este efeito não foi significativo para a maioria das variáveis estudadas. Esse resultado pode ser função de alguns fatores. Os animais eram inteiros e abatidos com baixo peso corporal ( $405 \mathrm{~kg}$ $\mathrm{PVz}$ ) e idade (14 meses) não sendo possível detectar diferenças já que estas se manifestam de forma mais clara posteriormente, no período em que há deposição mais intensa de gordura (i.e. a pesos mais elevados). As diferenças genéticas se limitavam ao efeito paterno, ou $50 \%$ da contribuição genética. A raça Guelbvieh possui tamanho intermediário, sem as características marcantes de elevado peso adulto de algumas raças Continentais. Quando comparados ao mesmo peso vivo, animais de tamanho corporal pequeno apresentam maior teor de gordura e menor teor de proteína que animais de tamanho corporal grande. Conseqüentemente, animais de maior tamanho corporal têm menor exigência de energia e maior exigência de proteína por quilo de ganho. Essas características não foram observadas na comparação destas raças, devido às características de tamanhos corporais intermediários de ambas as raças. 
Tabela 2 - Ganhos diários no período experimental

Table 2 - Daily gain in the experimental period

\begin{tabular}{|c|c|c|c|c|c|c|c|}
\hline \multirow[t]{2}{*}{$\begin{array}{l}\text { Variáveis } \\
\text { Variables }\end{array}$} & \multicolumn{3}{|c|}{$\begin{array}{l}\text { Nível de BIN }^{1} \\
\text { Level of BIN }\end{array}$} & \multicolumn{2}{|c|}{$\begin{array}{c}\text { Tipo genético } \\
\text { Breed }\end{array}$} & \multirow{2}{*}{$\begin{array}{c}\text { Interação } \\
\text { Interaction } \\
\mathrm{RxF}^{4}\end{array}$} & \multirow[t]{2}{*}{$\mathrm{CV}^{5}$} \\
\hline & $9 \%$ & $15 \%$ & $21 \%$ & $\mathrm{C}^{2}$ & $\mathrm{~B}^{3}$ & & \\
\hline $\begin{array}{l}\text { Peso vazio inicial, } \mathrm{kg} \\
\text { Initial empty body weight }\end{array}$ & 245,7 & 244,7 & 238,7 & 251,5 & 234,6 & 0,84 & 12,57 \\
\hline $\begin{array}{l}\text { Peso vazio final, } \mathrm{kg} \\
\text { Final empty body weight }\end{array}$ & 401,8 & 418 & 396,5 & 409,9 & 401,0 & 0,77 & 11,28 \\
\hline $\begin{array}{l}\text { Ganho peso vazio, } \mathrm{g} / \mathrm{d} \\
\text { Daily empty body gain }\end{array}$ & 1.100 & 1.210 & 1.110 & 1.100 & 1.180 & 0,76 & 17,04 \\
\hline $\begin{array}{l}\text { Água, g/d } \\
\text { Water }\end{array}$ & 528 & 563 & 569 & 537 & 569 & 0,97 & 26,11 \\
\hline $\begin{array}{l}\text { Extrato etéreo, } \mathrm{g} / \mathrm{d} \\
\text { Ether extract }\end{array}$ & 316 & 374 & 283 & 311 & 337 & 0,42 & 35,03 \\
\hline $\begin{array}{l}\text { Proteína, g/d } \\
\text { Protein }\end{array}$ & 203 & 223 & 207 & 204 & 218 & 0,87 & 17,59 \\
\hline $\begin{array}{l}\text { Cinza, g/d } \\
\text { Ash }\end{array}$ & 50 & 55 & 51 & 50 & 54 & 0,88 & 17,65 \\
\hline $\begin{array}{l}\text { Energia, Mcal/d } \\
\text { Energy }\end{array}$ & 4,11 & 4,77 & 3,81 & 4,07 & 4,39 & 0,41 & 26,93 \\
\hline
\end{tabular}

${ }^{1}$ Bagaço in natura (In natura bagasse); ${ }^{2}$ Continental; ${ }^{3}$ Britânicos (British); ${ }^{4}$ Interação Raça x Fibra (Breed x Fiber interaction); ${ }^{5}$ Coeficiente de variação (Coefficient of variation).

Tabela 3 - Composição do corpo vazio ao abate

Table 3 - Final empty body composition

\begin{tabular}{|c|c|c|c|c|c|c|c|}
\hline \multirow[t]{2}{*}{$\begin{array}{l}\text { Variáveis } \\
\text { Variables }\end{array}$} & \multicolumn{3}{|c|}{$\begin{array}{l}\text { Nível de BIN } \\
\text { Level of BIN }\end{array}$} & \multicolumn{2}{|c|}{$\begin{array}{c}\text { Tipo genético } \\
\text { Breed }\end{array}$} & \multirow{2}{*}{$\begin{array}{c}\text { Interação } \\
\text { Interaction } \\
\mathrm{RxF}^{4} \\
\end{array}$} & \multirow[t]{2}{*}{$\mathrm{CV}^{5}$} \\
\hline & $9 \%$ & $15 \%$ & $21 \%$ & $\mathrm{C}^{2}$ & $\mathrm{~B}^{3}$ & & \\
\hline Água, \% & 58,0 & 56,7 & 59,1 & 58,3 & 57,7 & 0,42 & 5,46 \\
\hline $\begin{array}{l}\text { Water } \\
\text { Extrato etéreo, \% } \\
\text { Ether extract }\end{array}$ & 18,2 & 19,5 & 17,0 & 17,9 & 18,6 & 0,42 & 18,7 \\
\hline $\begin{array}{l}\text { Proteína bruta, \% } \\
\text { Crude protein }\end{array}$ & 19,1 & 19,0 & 19,2 & 19,1 & 19,1 & 0,42 & 1,02 \\
\hline $\begin{array}{l}\text { Cinza, } \% \\
\text { Ash }\end{array}$ & 4,7 & 4,8 & 4,7 & 4,7 & 4,6 & 0,48 & 1,02 \\
\hline $\begin{array}{l}\text { Energia Mcal/kg } \\
\text { Energy }\end{array}$ & 2,76 & 2,89 & 2,66 & 2,74 & 2,80 & 0,48 & 11,31 \\
\hline
\end{tabular}

${ }^{1}$ Bagaço in natura (In natura bagasse); ${ }^{2}$ Continental; ${ }^{3}$ Britânicos (British); ${ }^{4}$ Interação Raça x Fibra (Breed x Fiber interaction); ${ }^{5}$ Coeficiente de variação (Coefficient of variation).

Entretanto, a deposição de gordura para os animais Britânicos foi cerca de $8 \%$ maior do que para animais Continentais, sugerindo que o genótipo Guelbvieh apresenta tendência de maior proporção de músculo no ganho. O teor de lipídeo no ganho de cerca de $28 \%$ e o teor de lipídeo final de $18 \%$ (em média) aos $400 \mathrm{~kg}$ de peso vazio foi menor que dados da literatura para touros britânicos (Anrique, 1976; Simpfendorfer, 1974). Na Figura 1 está representada a relação entre peso do corpo vazio e da gordura de touros Angus e Holandeses comparados com os animais Britânicos e Continentais deste experimento.
Os resultados sugerem que os tourinhos deste experimento apresentavam composição próxima a tourinhos Holandeses. Com animais Santa Gertrudis, Berndt et al. (1999) encontraram teor de lipídeo no ganho de $42 \%$ e o teor de lipídeo final de $22 \%$ aos $407 \mathrm{~kg}$ de peso vazio, embora estes animais tenham recebido suplementação pré-desmama e maior tempo de confinamento.

Trabalhando com animais de dois anos de idade, Lanna et al. (1997) estudaram a composição corporal de três diferentes grupos genéticos Nelore, Nelore $\mathrm{x}$ Marchigiana, e mestiços leiteiros com sangue holandês e encontraram teores de lipídeo no corpo vazio 


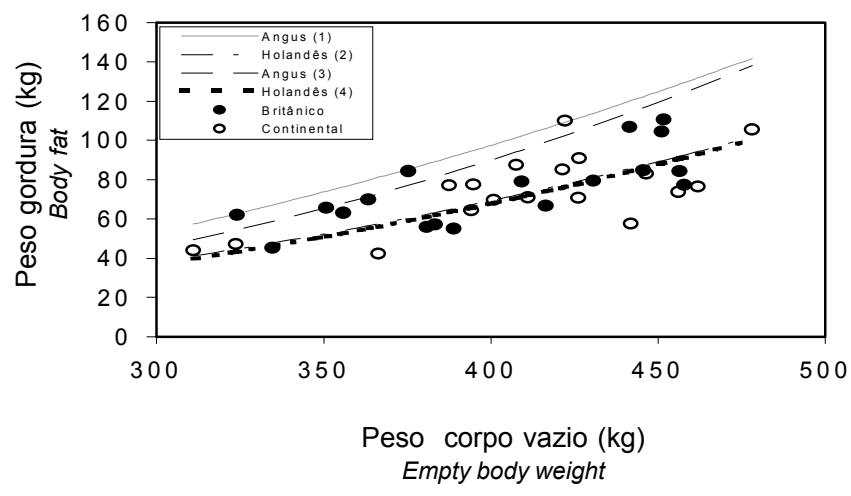

Figura 1 - Comparação da deposição de gordura dos tourinhos deste trabalho (círculos) com equações desenvolvidas em trabalhos similares com animais inteiros das raças Holandesa e Angus.

Figure 1 - Deposition of body fat in bulls from this trial (circles) and from the literature.

(1) Touros Angus, segundo equação de Anrique: $y=2,7803-$ $0,03778 x+0,0006872 x^{2}$ In: (Anrique, 1976)

(2) Touros Holandeses, segundo equação de Anrique: $y=17,5808$ $-0,11076 x+0,0005997 x^{2}$ In: (Anrique, 1976)

(3) Touros Angus segundo equação de Simpfendorfer: $y=28,429$ $-0,2342 x+0,00097 x^{2}$ In: (Simpfendorfer, 1974)

(4) Touros Holandeses segundo equação de Simpfendorfer: $y=$ $16,403-0,1115 x+0,00060 x^{2}$ In: (Simpfendorfer, 1974)

final de 19, 16 e 18\% respectivamente. Estes teores baixos de gordura, apesar do elevado peso de abate ( $500 \mathrm{~kg})$, também são função dos animais serem machos inteiros, além de estarem em crescimento compensatório. Na verdade, a maior parte dos abates no Brasil é realizado com baixa proporção de gordura, seja com bois confinados após período prolongado de pastejo, seja com garrotes confinados imediatamente após a desmama, como no presente trabalho, mas abatidos com pesos inferiores a $480 \mathrm{~kg}$. Comparativamente, os teores de lipídeos nos animais abatidos nos Estados Unidos e Canadá são de cerca de $28 \%$. Quando os abates são conduzidos neste grau de acabamento, as diferenças raciais são mais evidentes.

$\mathrm{O}$ efeito de fibra não foi significativo para as variáveis estudadas, mas os animais recebendo dietas com $15 \%$ de BIN apresentaram uma taxa numericamente maior de ganho de peso vazio. Consistente com este ganho maior, a composição do ganho conteve maior porcentagem numérica de extrato etéreo (Tabelas 2 e 4). Trabalhos anteriores do nosso grupo demonstraram que o BIN apresentou resultados de desempenho inferiores aos da silagem de milho, quando usado como única fonte de fibra para dietas de alto concentrado (Henrique et al., 1999a). Berndt et al. (1999), comparando milho seco ou ensilado úmido associado à silagem de milho ou BIN em tourinhos Santa Gertrudis, verificou redução no teor de energia líquida da dieta contendo BIN. Houve também tendência de aumento no teor de gordura final no corpo vazio dos animais que receberam silagem em relação àqueles que receberam $\mathrm{BIN}$, fato que pode estar ligado ao maior ganho de peso e peso vazio final dos animais recebendo silagem. Em função da baixa variação na taxa de ganho, não se esperava encontrar, neste trabalho, grandes diferenças na composição do ganho dos animais alimentados com os três diferentes níveis de fibra.

Os resultados do teor de nitrogênio na forma de úreia no plasma dos animais estão de acordo com a

Tabela 4 - Composição do ganho de corpo vazio

Table 4 - Composition of the empty body gain

\begin{tabular}{|c|c|c|c|c|c|c|c|}
\hline \multirow[t]{2}{*}{$\begin{array}{l}\text { Variáveis } \\
\text { Variables }\end{array}$} & \multicolumn{3}{|c|}{$\begin{array}{l}\text { Nível de BIN }{ }^{1} \\
\text { Level of BIN }\end{array}$} & \multicolumn{2}{|c|}{$\begin{array}{c}\text { Tipo genético } \\
\text { Breed }\end{array}$} & \multirow{2}{*}{$\begin{array}{c}\text { Interação } \\
\text { Interaction } \\
\qquad \mathrm{RxF}^{4}\end{array}$} & \multirow[t]{2}{*}{$\mathrm{CV}^{5}$} \\
\hline & $9 \%$ & $15 \%$ & $21 \%$ & $\mathrm{C}^{2}$ & $\mathrm{~B}^{3}$ & & \\
\hline Água, \% & 48,4 & 46,1 & 51,0 & 48,9 & 48,1 & 0,64 & 18,38 \\
\hline $\begin{array}{l}\text { Water } \\
\text { Extrato etéreo, \% } \\
\text { Ether extract }\end{array}$ & 28,6 & 31,0 & 25,7 & 28,0 & 28,9 & 0,64 & 33,75 \\
\hline $\begin{array}{l}\text { Proteína bruta, \% } \\
\text { Crude protein }\end{array}$ & 18,5 & 18,4 & 18,7 & 18,5 & 18,5 & 0,64 & 2,97 \\
\hline $\begin{array}{l}\text { Cinza, \% } \\
\text { Ash }\end{array}$ & 4,57 & 4,53 & 4,61 & 4,58 & 4,56 & 0,65 & 2,99 \\
\hline $\begin{array}{l}\text { Energia Mcal } / \mathrm{kg} \\
\text { Energy }\end{array}$ & 3,72 & 3,94 & 3,46 & 3,67 & 3,75 & 0,64 & 23,76 \\
\hline
\end{tabular}

${ }^{1}$ Bagaço in natura (In natura bagasse); ${ }^{2}$ Continental; ${ }^{3}$ Britânicos (British); ${ }^{4}$ Interação Raça x Fibra (Breed x Fiber interaction); ${ }^{5}$ Coeficiente de variação (Coefficient of variation). 
Tabela 5 - Teor de nitrogênio na forma de uréia no plasma Table 5 - Plasma urea nitrogen

\begin{tabular}{lcccccc}
\hline Variáveis & \multicolumn{3}{c}{$\begin{array}{c}\text { Nível de BIN } \\
\text { Level of } \text { BIN }^{2}\end{array}$} & & \multicolumn{2}{c}{$\begin{array}{c}\text { Tipos genéticos } \\
\text { Genetic types }\end{array}$} \\
\cline { 2 - 4 } \cline { 6 - 7 } & $9 \%$ & $15 \%$ & $21 \%$ & & $\mathrm{C}^{3}$ & $\mathrm{~B}^{4}$ \\
\hline $\mathrm{PUN}, \mathrm{mg} / \mathrm{dL}$ & 13,89 & 14,12 & 16,29 & & 14,92 & 14,61 \\
\hline
\end{tabular}

composição das dietas e com as taxas de deposição de proteína observadas, não havendo diferenças entre os dois tipos genéticos estudados; Britânicos $(14,61 \mathrm{mg} / \mathrm{dL})$ e Continentais $(14,92 \mathrm{mg} / \mathrm{dL})$ e entre os três níveis de BIN 9\% $(13,89 \mathrm{mg} / \mathrm{dL}) ; 15 \%$ $(14,12 \mathrm{mg} / \mathrm{dL}) ; 21 \%(16,29 \mathrm{mg} / \mathrm{dL})$.

\section{Conclusões}

As composições do corpo vazio e do ganho de corpo vazio de tourinhos $3 / 4$ europeus filhos de vacas Caracu x Nelore foram similares às observadas para animais europeus de tamanho corporal grande. $\mathrm{Na}$ faixa de peso estudada, a concentração de energia no ganho de peso foi menor que a estimada para tourinhos de tamanho corporal médio (NRC, 1984).

Os diferentes níveis de BIN não alteraram a composição do ganho, consistente com a pequena diferença no ganho de peso entre os tratamentos.

Até o peso de abate estudado, não houve efeito da raça paterna, Guelbvieh ou Shorthorn, na composição do ganho, apesar da tendência numérica para o ganho da última conter mais gordura. Estes resultados podem ser utilizados para parametrizar modelos de simulação do desempenho e de estimativa das exigências nutricionais.

\section{Agradecimento}

À Coimbra S.A. e FAPESP, pelo financiamento deste pesquisa.

\section{Literatura Citada}

ALLEONI, G.F.; LEME, P.R.; BOIN, C. et al. Métodos indiretos para estimar a composição química da carcaça de novilhos nelore. 2. Cortes da costela. In: REUNIÃO ANUAL DA SOCIEDADE BRASILEIRA DE ZOOTECNIA, 34., 1997, Juiz de Fora. Anais... Juiz de Fora: Sociedade Brasileira de Zootecnia, 1997. p.320-322.

ANRIQUE, R. Body composition and efficiency of cattle as

R. Bras. Zootec., v.31, n.1, p.436-443, 2002 (suplemento) related to body type, size and sex. Ithaca: Cornell University, 1976. $211 \mathrm{p}$. Thesis (PhD) - Cornell University, 1976.

BERNDT, A.; LANNA, D.P.D.; LEME, P.R. et al. Milho úmido, bagaço de cana e silagem de milho em dietas de alto concentrado. 2. Composição corporal e taxas de deposição dos tecidos In: REUNIÃO ANUAL SOCIEDADE BRASILEIRA DE ZOOTECNIA, 36., 1999, Porto Alegre. Anais... Porto Alegre: Sociedade Brasileira de Zootecnia, 1999. p.285.

BOIN, C.; LEME, P.R.; LANNA, D.P.D. Alguns dados sobre exigências de energia e de proteína de zebuínos. In: SIMPÓSIO INTERNACIONAL SOBRE EXIGÊNCIAS NUTRICIONAIS DE RUMINANTES, 1995, Viçosa - MG. Anais... Viçosa, MG: Universidade Federal de Viçosa, 1995. p.457-465.

BOIN, C.; LEME, P.R.; LANNA, D.P.D. et al. Tourinhos Nelore em crescimento e acabamento. 2. Exigências de energia líquida de mantença e eficiência de utilização da energia metabolizável para mantença e crescimento. In: REUNIÃO ANUAL DA SOCIEDADE BRASILEIRA DE ZOOTECNIA, 31., 1994, Maringá. Anais... Maringá: Sociedade Brasileira de Zootecnia, 1994. p.473.

FONTES, C.A.A. Composição corporal, exigências líquidas de nutrientes para ganho de peso e desempenho produtivo de animais zebuínos e mestiços europeu-zebu. Resultados experimentais. In: SIMPÓSIO INTERNACIONAL SOBRE EXIGÊNCIAS NUTRICIONAIS DE RUMINANTES, 1995, Viçosa, MG. Simpósio... Viçosa: Universidade Federal de Viçosa, 1995. p.419-455.

FOX, D.G.; SNIFFEN, C.J.; O'CONNOR, J.D. et al. A net carbohydrate and protein system for evaluating cattle diets: III. Cattle requeriments and diet adequacy. Journal Animal Science, v.70, p.3578-3596, 1992.

HANKINS, O.G.; HOWE, P.E. Estimation of the composition of beef carcasses and cuts. Washington: USDA, 1946. 20p. (USDA. Tech. Bulletin)

HENRIQUE, W.; LEME, P.R.; LANNA, D.P.D. et al. Equações para estimativa da composição química corporal de bovinos Santa Gertrudis a partir do corte da $9^{\mathrm{a}}-10^{\mathrm{a}}-11^{\mathrm{a}}$ costelas. In: REUNIÃO ANUAL DA SOCIEDADE BRASILEIRA DE ZOOTECNIA, 36., 1999, Porto Alegre. Anais... Porto Alegre: Sociedade Brasileira de Zootecnia, 1999a.

HENRIQUE, W.; LEME, P.R.; LANNA, D.P.D. et al. Avaliação do milho úmido com bagaço de cana ou silagem de milho na engorda de bovinos. I. Desempenho animal e características da carcaça. In: REUNIÃO ANUAL SOCIEDADE BRASILEIRA DE ZOOTECNIA, 36., 1999, Porto Alegre. Anais... Porto Alegre: Sociedade Brasileira de Zootecnia, 1999b. p.307.

HOPPER, T.H. Methods of estimating the physical and chemical composition of cattle. Journal of Agricultural Research, v.68, p.6, 1944.

LANA, R.P.; FONTES, C.A.A.; PERON, A.J. et al. Composição corporal e do ganho de peso e exigências de energia, proteína e macroelementos minerais ( $\mathrm{Ca}, \mathrm{P}, \mathrm{Mg}$ e $\mathrm{K}$ ) de novilhas de cinco grupos raciais. Conteúdo corporal e do ganho de peso em gordura, proteína e energia. Revista da Sociedade Brasileira de Zootecnia, v.21, p.518, 1992.

LANNA, D.P.D. Estimativa da composição química do corpo vazio de tourinhos Nelore através da gravidade específica da carcaça e da composição de cortes das costelas. Piracicaba: Escola Superior de Agricultura "Luiz de Queiroz", 1988. 131p. Dissertação (Mestrado em Nutrição Animal) - Escola Superior de Agricultura "Luiz de Queiroz”, 1988. 
LANNA, D.P.D.; LEME, P.R.; BOIN, C. et al. Ganho compensatório de bovinos de diferentes grupos genéticos: composição química e física corporal. In: REUNIÃO DA SOCIEDADE BRASILEIRA DE ZOOTECNIA, 34., 1997, Juiz de Fora. Anais... Juiz de Fora: Sociedade Brasileira de Zootecnia, 1997. p.352-54.

LANNA, D.P.D.; BOIN, C.; ALLEONI, G.F. et al. Estimation of carcass and empty body composition of zebu bulls using the composition of rib cuts. Scientia Agricola, v.52, n.1, p.189-97, 1995.

LANNA, D.P.D.; TEDESCHI, L.O.; BELTRAME FILHO, J.A. Modelos lineares e não-lineares de uso de nutrientes para formação de dietas de ruminantes. Scientia Agricola, v.56, n.2, p.479-88, 1999.

LEME, P.R.; BOIN, C.; ALLEONI, G.F. et al. Estimativa da composição química corporal de novilhos Nelore através do espaço de deutério. Revista da Sociedade Brasileira de Zootecnia, v.26, n.3, p.351-362, 1994.

LEME, P.R.; HENRIQUE, W.; LANNA, D.P.D. et al. Substituição do milho pela polpa de citrus em dietas de bovinos confinados. II. Composição química corporal e taxas de deposição. In: SOCIEDADE BRASILEIRA DE ZOOTECNIA, 34., 1997. Juiz de Fora. Anais... Juiz de Fora: Sociedade Brasileira de Zootecnia, 1997, p.358-360.

NATIONAL RESEARCH COUNCIL - NRC. Nutrient requirements of beef cattle. Washington: National Academy of Science, 1984. 90p

NATIONAL RESEARCH COUNCIL - NRC. Nutrient requirements of beef cattle. Washington: National Academy of Science, 1996. 242p.
ROBELIN, J.; GEAY, Y. Body composition of cattle as affected by physiological status, breed, sex and diet. In: GILCHRIST, F.M.C.; MACKIE, R.I. (Eds.) Herbivore nutrition in the subtropics and tropics. Petroria: The Science Press, 1983. p.525-548.

SAS. INSTITUTE. SAS/STAT: user's guide. Cary: 1997.

SIMPFENDORFER, S. Relationship of body type and size, sex and energy intake to the body composition of cattle. Ithaca: University of Cornell, 1974. 193p. Thesis (PhD) University of Cornell, 1974.

WEISS, W.P.; CONDAD, H.R.; St. PIERRE, N.R. et al. A theoretical-based model for predicting total digestible nutrient values of forages and concentrates. Animal Feed Science Technology, v.39, p.95-110, 1992.

Recebido em: 26/07/00

Aceito em: 24/09/01 